\title{
Efeito do treinamento físico sobre o tecido ósseo e a concentração sérica de cálcio em camundongos fêmeas ovariectomizadas ${ }^{1}$
}

\author{
Effect of physical training on the bone tissue and the calcium serum concentration in \\ ovariectomized mice.
}

\begin{abstract}
Angélica da Silva Tenório², Simone Bezerra Alves ${ }^{3}$, Andrezza de Lemos Bezerra ${ }^{4}$, Grace Mary Lima Souza ${ }^{5}$, Maria Teresa Jansen de Almeida Catanho ${ }^{6}$, Tetsuo Tashiro ${ }^{7}$, Lígia Cristina Monteiro Galindo ${ }^{8}$, Sílvia Regina Arruda de Moraes ${ }^{9}$
\end{abstract}

1. Dissertação apresentada no Mestrado em Biofísica da Universidade Federal de Pernambuco.

2. Professora da Faculdade do Agreste de Pernambuco / ASCES-Associação Caruaruense de Ensino Superior.

3. Doutoranda do Programa de Pós-Graduação em Biologia da UERJ.

4. Mestranda do Programa de Pós-Graduação em Ciências Biológicas da UFPE.

5. Doutoranda do Programa de Pós-Graduação em Ciências Farmacêuticas da UFPE.

6. Professora Adjunto do Departamento de Biofísica e Radiobiologia da UFPE.

7. Professor Assistente do Departamento de Educação Física da UFPE.

8. Mestranda do Curso de Pós-Graduação em Anatomia Patológica da UFPE.

9. Professora Adjunto do Departamento de Anatomia da UFPE.

\section{RESUMO}

Objetivo: Investigar as possíveis alterações morfométricas no tecido ósseo e na concentração sérica de cálcio em camundongos ovariectomizadas submetidas ao treinamento físico. Métodos: Cinqüenta camundongos fêmeas, com 90 dias de idade, distribuídos em 5 grupos $(n=10)$ : controle (C), pseudo-operado sedentário (POS), pseudo-operado treinado (POT), ovariectomizado sedentário (OVS) e ovariectomizado treinado (OVT). Os grupos OVS e OVT foram submetidos a ovariectomia, e os grupos POS e POT a uma pseudo-cirurgia. Trinta dias após a cirurgia, os grupos POT e OVT foram submetidos ao exercício físico, durante 05 semanas em esteira elétrica a uma velocidade de $20 \mathrm{~m} / \mathrm{min}$. Os demais animais permaneceram sedentários no mesmo período. Após esse período os animais foram sacrificados, coletando o sangue para realização de dosagens séricas de cálcio e os fêmures direitos para estudo histomorfométrico. Resultados: A concentração sérica de cálcio no grupo OVT apresentou-se mais baixa do que nos demais grupos $(\mathrm{p}<0,05)$. A massa dos fêmures mostrou-se superior em relação ao grupo controle, nos grupos POT e OVT $(\mathrm{p}<0,05)$. A densidade média de osteócitos foi mais alta no grupo OVS $(\mathrm{p}<0,05)$. O valor médio da área dos osteócitos mostrou diferença apenas entre os grupos POS e OVS ( $\mathrm{p}<0,05)$. Não houve diferenças no comprimento ósseo nem no perímetro dos osteócitos. Conclusão: O exercício, em parte, preveniu as alterações do tecido ósseo decorrentes da ovariectomia e possibilitou um aumento da formação óssea. Descritores: Metabolismo ósseo. Treinamento físico. Ovariectomia.

\begin{abstract}
Purpose: The aim of this study is to evaluate possible morphometric alterations in bone tissue and the calcium serum concentration in ovariectomized mice subjected to physical training. Methods: Fifty female mice, aged 90 days, divided into 5 groups $(\mathrm{n}=10)$ : control $(\mathrm{C})$, pseudo-operated sedentary (POS), pseudo-operated trained (POT), ovariectomized sedentary (OVS) and ovariectomized trained (OVT). Groups OVS and OVT were subjected to an ovariectomy, and groups POS and POT were subjected to a pseudo-surgery. Thirty days after the surgery, groups POT and OVT were subjected to physical training during 05 weeks in ergometer at a speed of $20 \mathrm{~m} / \mathrm{min}$. The other animals stayed sedentary at the same period. Afterwards the animals were sacrificed and had blood collected to realize calcium serum dosage and the rigth femurs were collected to realize a histomorphometric study. Results: The calcium serum concentration in group OVT was lower than the other groups $(\mathrm{p}<0,05)$. The mass of femurs in groups POT and OVT was higher than the group Control $(p<0,05)$. The average density of the osteocytes was higher in group OVS $(p<0,05)$. The average value of the area of the osteocytes showed difference only between groups POS and OVS $(p<0,05)$. There were no differences in the bone length, nor in the osteocytes perimeter. Conclusion: The physical training in part prevented the alterations in the bone tissue due to the ovariectomy and enabled an increase of the bone formation.
\end{abstract}

Key words: Bone metabolism. Physical training. Ovariectomy. 


\section{Introdução}

A osteoporose é uma patologia óssea sistêmica caracterizada por um desequilíbrio entre reabsorção e formação óssea, resultando em um aumento da fragilidade óssea $^{1,2}$. A deficiência estrogênica é a causa mais comum de osteoporose, e o modelo animal que melhor representa a redução de massa óssea após a menopausa é a rata ovariectomizada, pois a redução de estrógenos observada neste modelo produz aumento na taxa de remodelação óssea com reabsorção superando a formação ${ }^{3}$. A ação do hormônio estrogênico sobre o tecido ósseo ainda não foi claramente definida, mas sabe-se que ele influencia a diferenciação de células progenitoras hematopoiéticas em osteoclastos e participa da regulação de citocinas e de fatores locais envolvidos nos mecanismos de remodelação óssea ${ }^{4}$. O exercício físico, por promover estímulo mecânico que leva à osteogênese, tem sido utilizado em diversas modalidades para se obter manutenção ou aumento da massa esquelética, tanto em estudos utilizando animais, como em humanos, sendo considerado uma estratégia para reduzir o risco de osteoporose $^{5,6}$. Estudos têm demonstrado que a prática de exercício físico regular é um fator importante na prevenção e tratamento da osteoporose ${ }^{7}$, porém, o mecanismo exato pelo qual a atividade física aumenta a massa óssea ainda não está esclarecido. Desta forma o objetivo deste estudo foi analisar as possíveis alterações sobre a morfologia celular de osteócitos da área cortical proximal do fêmur e nas concentrações séricas de cálcio de camundongos ovariectomizadas submetidas ao treinamento físico em esteira.

\section{Métodos}

Foram utilizados 50 camundongos albinos, "swiss" (Mus musculus), fêmeas, com 90 dias de idade, pesando, inicialmente 25-35 g., mantidos no biotério do Departamento de Biofísica e Radiobiologia da UFPE. Os animais foram distribuídos aleatoriamente em cinco grupos compostos por 10 animais: Controle; OVS: Ovariectomizado Sedentário; OVT: Ovariectomizado Treinado; POS: Pseudo-operado Sedentário; POT: Pseudo-operado Treinado.

No início do experimento, os animais dos grupos OVT e OVS foram submetidos a cirurgia para retirada dos ovários, enquanto que os animais dos grupos POS e POT foram submetidos a uma pseudo-cirurgia, sendo realizada uma pequena incisão atingindo apenas pele e tecido subcutâneo, que foram suturados logo em seguida. Para este procedimento cirúrgico os animais foram anestesiados via subcutânea com uma solução de cloridrato de xilazina (Rompum ${ }^{\circledR}$ - Bayer) (10 mg/Kg) e quetamina (Ketalar ${ }^{\circledR}$ ) (25mg/Kg). O grupo controle não foi submetido a qualquer procedimento cirúrgico.

Para a realização do protocolo de treinamento físico foi confeccionada uma esteira medindo $35 \mathrm{X} 15 \mathrm{~cm}$, com paredes montadas em material plástico (LEGO-DACTA ${ }^{\text {â }}$ e piso emborrachado, motor de 2,5 Ampers - 30 Watts, e controle de velocidade de 15 a $20 \mathrm{~m} / \mathrm{min}$., movida a eletricidade. Os animais dos grupos OVT e POT foram exercitados a uma velocidade de $20 \mathrm{~m} . / \mathrm{min} .{ }^{8,9}$, trinta dias após a cirurgia, durante 5 semanas, com aumento progressivo do tempo de treino: $1^{\text {a }}$ semana $-5 \mathrm{~min} / \mathrm{dia} ; 2^{\mathrm{a}}$ semana - $10 \mathrm{~min} / \mathrm{dia}$; $3^{\mathrm{a}}$ semana $-14 \mathrm{~min} / \mathrm{dia}$; $4^{\mathrm{a}}$ e $5^{\mathrm{a}}$ semanas $-20 \mathrm{~min} / \mathrm{dia}$. Os animais dos grupos OVS, POS e controle não foram submetidos ao treinamento. Ao término do treinamento, os animais foram submetidos ao procedimento anestésico descrito anteriormente, coletou-se o sangue por punção cardíaca, e em seguida ao sacrifício dos animais, foi realizada uma incisão da região abdominal inferior até o joelho direito, desinseridos os músculos e tendões das regiões anterior e posterior da coxa e desarticulado o fêmur direito em toda a sua extensão. Após a coleta os fêmures foram dissecados e descarnados, pesados em balança digital (precisão de $0,1 \mathrm{mg}$ ) e mensurados com régua milimetrada. Posteriormente foram realizados cortes transversais para obtenção de amostras da diáfise proximal do fêmur. Em seguida as amostras foram fixadas em solução fixadora de formol tamponado por um período de 72 horas e descalcificadas em ácido nítrico a 5\% durante 48 horas. $\mathrm{O}$ material foi incluído em parafina e obtidos 03 cortes de $4 \mu \mathrm{m}$ de espessura para cada amostra no sentido longitudinal do osso. Os cortes foram corados com hematoxilina e eosina (HE).

\section{Dosagem sérica do cálcio}

O soro obtido foi centrifugado a 3.000 rpm e para a determinação do cálcio, utilizou-se o método proposto pela Labtest-Diagnóstica (Brasil), no qual se utiliza um reagente aquoso estabilizado. O método colorimétrico foi usado para determinar o cálcio sérico. Medido em espectrofotômetro (Gehaka G3410, Brasil) a $570 \mathrm{~nm}$ da cor produzida pelo complexo formado entre ortocresoftaleína complexona e o cálcio, em pH alcalino.

\section{Estudo histomorfométrico}

A análise histomorfométrica das lâminas foi realizada em microscópio óptico (Olympus BH-2) com aumento de $400 X$. Foram escolhidos aleatoriamente 5 campos microscópicos por lâmina e através de software (TCI pro for Windows 95), as imagens foram capturadas para o microcomputador e analisadas por meio do software Optimas 6.1, através do qual foram determinados a densidade de osteócitos por campo e a área e o perímetro destas células, localizadas na área cortical proximal do fêmur.

Para a comparação entre os diferentes grupos foi empregado o teste de Tukey. A significância estatística foi considerada admitindo-se um nível crítico de 5\% em todos os casos.

\section{Resultados}

As figuras 1, 2 ,3 e 4 representam os valores obtidos para a análise da concentração sérica de cálcio, massa femoral, densidade e área dos osteócitos, respectivamente. Não foram observadas diferenças, com relação ao comprimento médio do fêmur $(\mathrm{p}>0,05)$ e o perímetro dos osteócitos ( $\mathrm{p}>0,05)$. 


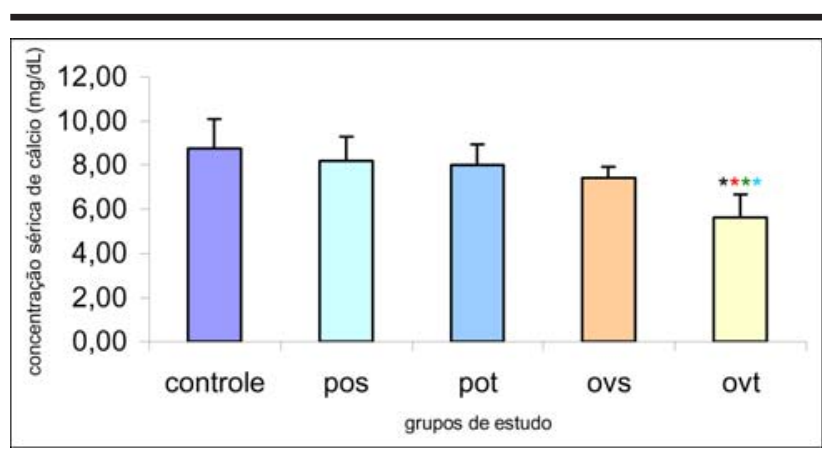

FIGURA 1 - Valores médios da concentração sérica de cálcio (mg/ dL) dos animais controle; pseudooperados sedentários (POS); pseudo-operados treinados (POT); ovariectomizados sedentários (OVS); ovariectomizados treinados (OVT). (*): Indica diferença em relação ao grupo controle, $\left({ }^{*}\right)$ : Indica diferença em relação ao grupo OVS, $(*)$ : Indica diferença em relação ao grupo POT, $\left({ }^{*}\right)$ : Indica diferença em relação ao grupo POS $(\mathrm{p}<0,05$ para 0 Teste de Tukey).

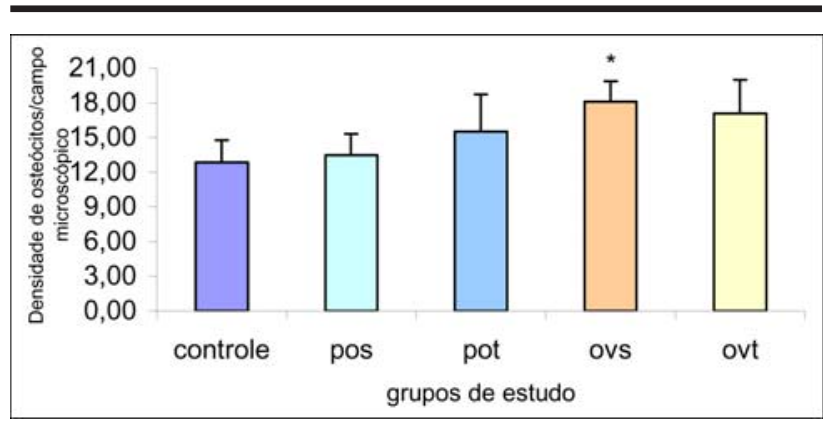

FIGURA 3 - Densidade média de osteócitos por campo microscópico nos grupos controle; pseudo-operados sedentários (POS); pseudo-operados treinados (POT); ovariectomizados sedentários (OVS) e ovariectomizados treinados (OVT). (*) Indica diferença em relação ao grupo controle $(\mathrm{p}<0,05$ para o Teste de Tukey).

\section{Discussão}

Nossos dados sugerem que o treinamento físico está relacionado com a redução da concentração sérica de cálcio em camundongos fêmeas submetidas a ovariectomia, e não exerce influência sobre os animais que tiveram os ovários preservados. Como os animais ovariectomizados treinados apresentaram ainda aumento da massa femoral, pode-se inferir que esta redução na concentração sérica de cálcio esteja relacionada a uma maior deposição de cálcio no osso, que não foi quantificada neste estudo, embora estudo com ratos Wistar machos submetidos a treinamento de esteira não tenha encontrado diferença no conteúdo de cálcio no fêmur ${ }^{10}$. Horcajada et al. ${ }^{8}$ não encontraram alteração significativa nos níveis plasmáticos de cálcio em ratos orquidectomizados submetidos a treinamento em esteira. Entretanto, observaram que o conteúdo de cálcio no fêmur esteve mais elevado nos animais treinados. Neste estudo, os animais ovariectomizados sedentários não apresentaram alterações nos níveis de cálcio sérico. Corroborando com estes achados, estudo utilizando ratas submetidas a ovariectomia, recebendo uma dieta contendo $0,1 \%$ de cálcio para representar a ingesta de cálcio consumida por mulheres na pós-menopausa, verificou que os animais

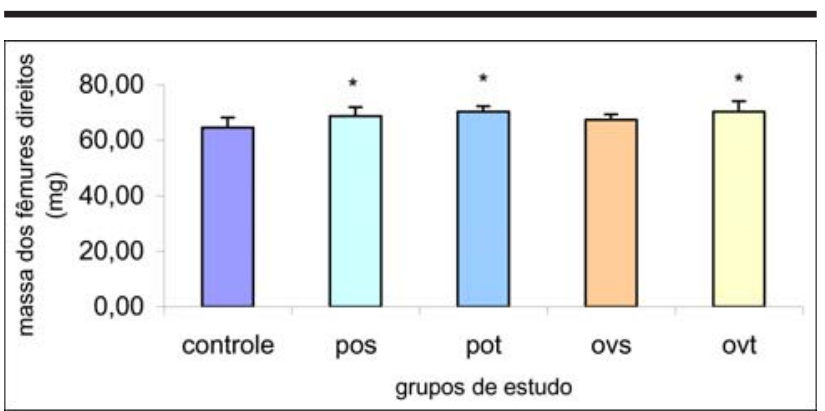

FIGURA 2 - Valores médios da massa (mg) dos fêmures direitos dos animais controle; pseudooperados sedentários (POS); pseudo-operados treinados (POT); ovariectomizados sedentários (OVS) e ovariectomizados treinados (OVT). (*) Indica diferença em relação ao grupo controle ( $\mathrm{p}<0,05$ para o Teste de Tukey).

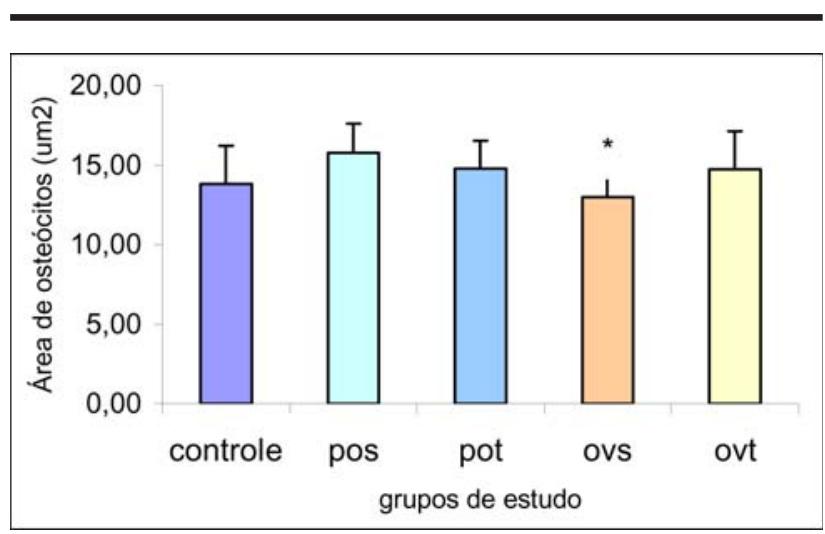

FIGURA 4 - Valores médios da Área dos osteócitos ( $\mu \mathrm{m} 2)$ nos grupos controle; pseudooperados sedentários (POS); pseudo-operados treinados (POT); ovariectomizados sedentários (OVS) e ovariectomizados treinados (OVT). (*): Indica diferença em relação ao grupo POS ( $\mathrm{p}<0,05$ para o Teste de Tukey).

ovariectomizados apresentaram perda óssea, mas não houve diferença significativa no cálcio plasmático total, em relação a animais submetidos à cirurgia simulada ${ }^{11}$. Sabe-se que os hormônios estrogênicos apresentam efeitos diretos sobre o osso, e também, sobre os rins e intestinos, órgãos que têm papéis importantes no transporte do cálcio, havendo geralmente aumento do cálcio plasmático total quando há deficiência estrogênica, como na menopausa ou após ovariectomia, e queda desta concentração com a realização de reposição estrogênica ${ }^{12}$. No entanto, ainda existem dúvidas sobre a influência do estrógeno sobre as diversas frações de cálcio contribuindo para a concentração do cálcio plasmático total. De acordo com os resultados aqui apresentados, os animais treinados, tanto ovariectomizados quanto pseudo-operados, mostraram discreto aumento da massa femoral em relação aos animais controle, o que sugere possível aumento da deposição mineral no osso, sobretudo nos animais ovariectomizados treinados, que apresentaram redução sérica de cálcio. Por outro lado, não houve alterações no tamanho do fêmur, provavelmente devido ao estado de maturação esquelética dos animais. Entretanto, estudos com animais mais jovens demonstraram aumento de massa óssea subseqüente ao exercício ${ }^{9,13}$. A adaptação esquelética ao estresse mecânico 
poderia ser explicada pela teoria mecanoestática ${ }^{13}$, segundo a qual o aumento do estímulo mecânico leva ao aumento na modelação e diminui a remodelação óssea. Em ossos jovens, tanto a modelação quanto a remodelação estão ativas, enquanto que em ossos adultos, a modelação está diminuída e a remodelação é predominante. Conseqüentemente, a resposta do osso ao exercício deve ser dependente de alterações da remodelação óssea, tanto em ratos adultos quanto em ratos jovens. Neste estudo, não se observou influência do treinamento físico sobre a histomorfometria óssea, porém, a ovariectomia associada ao sedentarismo esteve relacionada à redução na área dos osteócitos, e possivelmente devido a esta redução, houve maior densidade de células por campo microscópico. A densidade de osteócitos sofre influências de alterações na diferenciação final de células da linhagem osteoblástica, podendo estar elevada na osteoporose, ou quando a mineralização da matriz óssea está prejudicada ${ }^{14}$. Os osteócitos teriam a função de regular o recrutamento de unidades básicas de modelação em resposta a estímulo mecânico, modulando a diferenciação de osteoblastos em osteócitos e aumentando a produção de fatores locais. Mullender et al ${ }^{15}$ verificaram maior densidade de osteócitos e maior densidade e menor área de lacunas osteocitárias em pacientes osteoporóticos, sugerindo que na osteoporose os osteócitos promovem menor volume ósseo e ocorre redução na vida média dos osteoblastos. Além disso, o tamanho dos osteócitos é proporcional ao tamanho dos osteoblastos dos quais eles se diferenciaram ${ }^{16}$.

\section{Conclusão}

O exercício, em parte, preveniu as alterações do tecido ósseo decorrentes da ovariectomia e possibilitou um aumento da formação óssea, evidenciado pela redução da concentração sérica de cálcio e o discreto aumento da massa femoral.

\section{Referências}

1.Goddard D, Kleerekoper M. The epidemiology of osteoporosis. Postgraduate Med. 1998, 104 (4): 54-72.

2. Rosen CJ, Tenenhouse A. Biochemical markers of bone turnover. Postgrad Med. 1998;104(4):101-14.

3. Bortoli MA, Ascar JM, Arce,P Villegas L. Variaciones en el contenido de calcio, fosfato, magnesio y sodio en huesos de ratas ovariectomizadas. Arch Latin Amer Nutr. 1996, 46(1): 38-41.

4.Raisz LG. Physiology and pathophysiology of bone remodeling. Clin Chem 1999, 45(8B):1353-8.

5. Kannus P, Jozsa L, Renström P, Järvinen M, Kvist M, Lehto M, Oja P, Vuori I. The effect of trainning, immobilization and remobilization on musculoskeletal tissue. 1. Trainning and immobilization. Scandinavian J Med Scien Sports. 1992;2:100-18.

6. Hart KJ, Shaw JM, Vajda E, Hegsted M, Miller SC. Swim - trained rats have greater bone mass, density, strenght, and dynamics. J Appl Physiol. 2001;91:1663-8.

7. Andrews WC. What's the new in preventing and treating osteoporosis? Postgraduate Medicine1998, 104 (4): 89-97.

8._Horcajada MN, Coxam V, Davicco MJ, Gaumet N, Pastoureau P, Leterrier C, Culioli J, Barlet JP. Influence of treadmill running on femoral bone in young orchidectomized rats. J Appl Physiol. 1997;83(1):129-33.

9. Kiuchi A, Arai Y, Katsuta S. Detraining effects on bone mass in young male rats. Inter J Sports Med. 1998;19:245-9.

10. Huang TH, Yang RS, Hsieh SS, Liu SH. Effects of caffeine and exercise on the development of bone: a densitometric and histomorphometric study in young wistar rats. Bone. 2002;30,(1):293-9.

11. Dick IM, St. John A, Heal S, Prince RL. The effect of estrogen deficiency on bone mineral density, renal calcium and phosphorus handling and calcitropic hormones in the rat. Calcified Tissue Intern 1996, 59: 174-8.

12. Prince RL. Counterpoint: estrogen effects on calcitropic hormones and calcium homeostasis. Endoc Reviw. 1994;15(3) :301-09.13. Iwamoto J, Yeh JK, Aloia F. Differential effect of treadmill exercise on three cancellous bone sites in the young growing rat. Bone. 1999; 24(3):163-9.

14. Power J, Loveridge N, Rushton N, Parker M, Reeve J. Osteocyte density in aging subjects is enhanced in bone adjacent to remodeling haversian sistems. Bone. 2002; 30(6):859-65.

15. Mullender MG, Van Der Meer D, Huiskes R, Lips P. Osteocyte density changes in aging and osteoporosis. Bone.1996;18(2):109-13.

16. Marotti G. The osteocyte as a wiring transmission system. J Musculoskeletal Neuron Interact. 2000;1(2):133-6.

\section{Correspondência:}

Sílvia Regina Arruda de Moraes

Universidade Federal de Pernambuco

Departamento de Anatomia - Centro de Ciências Biológicas

50670-420 - Recife-PE

silvia@ufpe.br
Conflito de interesse: nenhum Fonte de financiamento: $\mathrm{CNPq}$

Recebimento: 23/02/2005

Revisão: $15 / 03 / 2005$

Aprovação: 19/04/2005

\section{Como citar este artigo:}

Tenório AS, Alve SB, Bezerra AL, Souza GML, Catanho MTJA, Tashiro T, Galindo LCM, Moraes SRA. Efeito do treinamento físico sobre o tecido ósseo e a concentração sérica de cálcio em camundongos fêmeas ovariectomizadas. Acta Cir Bras. [periódico na internet] 2005 Jul-Ago;20(4). Disponível em URL: http://www.scielo.br/acb 